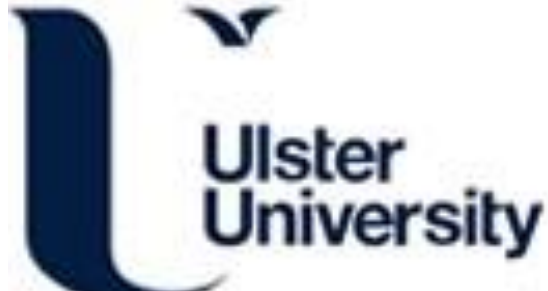

\section{Synthesis of Copper-Based Nanostructures in Liquid Environments by Means of a Non-equilibrium Atmospheric Pressure Nanopulsed Plasma Jet}

Liguori, A., Gallingani, T., Padmanaban, D. B., Laurita, R., Velusamy, T., Jain, G., Macias-Montero, M., Mariotti, D., \& Gherardi, M. (2018). Synthesis of Copper-Based Nanostructures in Liquid Environments by Means of a Non-equilibrium Atmospheric Pressure Nanopulsed Plasma Jet. Plasma Chemistry and Plasma Processing, 38(6), 1209-1222. https://doi.org/10.1007/s11090-018-9924-0

Link to publication record in Ulster University Research Portal

Published in:

Plasma Chemistry and Plasma Processing

Publication Status:

Published (in print/issue): 01/11/2018

DOI:

10.1007/s11090-018-9924-0

\section{Document Version}

Author Accepted version

\section{General rights}

Copyright for the publications made accessible via Ulster University's Research Portal is retained by the author(s) and / or other copyright owners and it is a condition of accessing these publications that users recognise and abide by the legal requirements associated with these rights.

\section{Take down policy}

The Research Portal is Ulster University's institutional repository that provides access to Ulster's research outputs. Every effort has been made to ensure that content in the Research Portal does not infringe any person's rights, or applicable UK laws. If you discover content in the Research Portal that you believe breaches copyright or violates any law, please contact pure-support@ulster.ac.uk. 


\title{
Synthesis of copper-based nanostructures in liquid environments by means of a non-equilibrium atmospheric pressure nanopulsed plasma jet
}

Anna Liguori ${ }^{1}$, Tommaso Gallingani ${ }^{2}$, Dilli Babu Padmanaban ${ }^{3}$, Romolo Laurita $^{2}$, Tamilselvan Velusamy ${ }^{3}$, Gunisha Jain ${ }^{3}$, Manuel Macias-Montero ${ }^{3}$, Davide Mariotti ${ }^{3}$, Matteo Gherardi $^{1,2} *$

${ }^{1}$ Advanced Mechanics and Materials, Interdepartmental Center for Industrial Research (AMM-ICIR), Alma Mater Studiorum-Università di Bologna, Via Saragozza 8, 40123 Bologna, Italy

${ }^{2}$ Department of Industrial Engineering (DIN), Alma Mater Studiorum-Università di Bologna, Via Saragozza 8, 40123, Bologna, Italy

${ }^{3}$ Nanotechnology \& Integrated Bio-Engineering Centre (NIBEC), Ulster University, Newtownabbey, Co Antrim, BT37 OQB, Northern Ireland, UK

* Correspondence and requests for materials should be addressed to Anna Liguori (anna.liguori@unibo.it) and Matteo Gherardi (matteo.gherardi4@unibo.it)

\begin{abstract}
The influence of the liquid composition on the chemical and morphological properties of copper-based nanostructures synthesized by a non-equilibrium atmospheric plasma treatment is investigated and discussed. The synthesis approach is simple and environmentally friendly, employs a non-equilibrium nanopulsed atmospheric pressure plasma jet as a contactless cathode and a $\mathrm{Cu}$ foil as immersed anode. The process was studied using four distinct electrolyte solutions composed of distilled water and either $\mathrm{NaCl}+\mathrm{NaOH}, \mathrm{NaCl}$ only or $\mathrm{NaOH}$ only at two different concentrations, without the addition of any copper salts. $\mathrm{CuO}$ crystalline structures with limited impurities (e.g. $\mathrm{Cu}$ and $\mathrm{Cu}(\mathrm{OH})_{2}$ phases) were produced from $\mathrm{NaCl}+\mathrm{NaOH}$ containing solutions, mainly $\mathrm{CuO}$ and $\mathrm{CuCl}_{2}$ structures were synthesized in the electrolyte solution containing only $\mathrm{NaCl}$ and no synthesis occurred in solutions containing only $\mathrm{NaOH}$. Both aggregated and dispersed nanostructures were produced in the $\mathrm{NaCl}+$ $\mathrm{NaOH}$ and $\mathrm{NaCl}$ containing solutions. Reaction pathways leading to the formation of the nanostructures are proposed and discussed.
\end{abstract}

Keywords: non-equilibrium atmospheric pressure plasma, synthesis of nanostructures, plasma-liquid interactions, reaction pathways, X-ray photoelectron spectroscopy, transmission electron microscopy.

\section{Acknowledgments}

This work was partially supported by the PLASMAT project (Alma Mater Studiorum—Università di Bologna, FARB grant) and by COST Action TD1208 Electrical Discharges with Liquids for Future Applications. The authors would like to acknowledge Prof. Vittorio Colombo, Prof. Maria Letizia Focarete and Prof. Catia Arbizzani for the fruitful scientific conversations. This work was also partially supported by EPSRC (award n.EP/M024938/1 and n.EP/K022237/1). 


\section{Introduction}

In recent years, the interactions between non-equilibrium (cold) atmospheric pressure plasmas (CAP) and liquids have attracted great interest due to their key role played in reaction mechanisms relevant for emerging fields such as plasma medicine $[1,2]$ and nanomaterials synthesis [3-5]. As widely documented, CAP can be the source of a broad range of reactive species, which initiate cascade reactions in the bulk of the liquid phase when interacting through the gas-liquid interface [6]. These reactions can induce the synthesis of nanostructures directly in solution when suitably designed plasma-liquid configurations are used [7-10].

In addition to CAP assisted approaches, wet-chemical (i.e. hydro/solvothermal synthesis, selfassembly, sonication) and electrochemical techniques have been employed over the years for the synthesis of nanostructures [11-15]. Among these techniques, electrochemical methods show similarities with the CAP assisted approach; these are based on the anodic dissolution of metal foils and subsequent reduction of metal cations at the solid cathode to obtain pure and size controlled nanostructures. However, isolating the reduction products without affecting their purity is rather difficult; in this respect CAP presents a remarkable advantage, since the replacement of a solid cathode with a contactless one allows the free nucleation and dispersion of the produced nanostructures [16]. An additional advantage is the possibility of synthesizing nanostructures without the need for surfactants or capping agents [17-19], which are typically required in wet chemical and electrochemical methods to avoid aggregation [14, 15, 20-23] but are generally responsible for nanostructures contamination. Recently, Mariotti et al. demonstrated the possibility of effectively employing a cathodic microplasma to synthesize surfactant-free and electrostatically stabilized $\mathrm{Au}$ nanoparticles of different sizes by varying the concentration of the Au precursor dissolved in deionized water [4]. The cathodic microplasma configuration was also employed to produce colloidal metal nanoparticles from a solid metal anode dipped in an electrolyte solution. Sankaran et al. reported on the use of a cathodic microplasma and an immersed solid Ag or Au foil, as anode, for the rapid production of colloidal metal nanoparticles in an acidic electrolyte solution of de-ionized water, in the presence of a stabilizing agent [3,7]; similarly, Du et al. proposed the production of $\mathrm{Cu}_{2} \mathrm{O}$ nanoparticles in an electrolyte solution by means of the cathodic microplasma configuration and using $\mathrm{a} \mathrm{Cu}$ foil as anode [5].

However, further investigations are still required to better understand the effects of the chemical composition and conductivity of the liquid environment on the characteristics of the plasma-produced nanostructures. In the present work, we have focused on these aspects by testing four distinct electrolyte solutions composed of distilled water and either $\mathrm{NaCl}+\mathrm{NaOH}, \mathrm{NaCl}$ or $\mathrm{NaOH}$ at two different concentrations; no surfactants, capping or stabilizing agents were added to the solutions. The experimental setup was completed by a nanopulsed CAP jet, as cathode, and a $\mathrm{Cu}$ foil partially immersed in the electrolyte solution as anode. Copper was chosen as the anode of the electrochemical 
cell since $\mathrm{Cu}$-based nanostructures (e.g. $\mathrm{CuO}, \mathrm{CuCl}_{2}, \mathrm{Cu}$ ) have raised interest for a wide range of applications, such as absorber in photovoltaic cells, catalyst and antimicrobial agents [24-27]. Morphological and chemical characterization of the obtained nanostructures was performed by transmission electron microscopy (TEM), selected area electron diffraction (SAED), X-ray diffraction (XRD) analysis and X-ray photoelectron spectroscopy (XPS). The chemical mechanisms leading to the synthesis of nanostructures in both electrolyte solutions are proposed and discussed with the support of the chemical characterization of the plasma-produced colloids.

\section{Experimental section}

\section{Non-equilibrium atmospheric pressure nanopulsed plasma jet}

The plasma source adopted in this work is a single electrode plasma jet (Figure 1a), which is suitable for different processes such as polymerization, co-deposition processes and for the treatment of various substrates [28-31]. The high-voltage electrode is a $19.5 \mathrm{~mm}$ long stainless steel sharpened metallic needle with a diameter of $0.3 \mathrm{~mm}$. The plasma plume is ejected from the source tip through an orifice with a diameter of $4 \mathrm{~mm}$. The plasma source was driven by a commercial pulsed DC generator (FID GmbH-FPG 20-1NMK) producing high-voltage pulses with a slew rate of 3-5 $\mathrm{kV} \mathrm{ns}^{-1}$, a pulse duration of about $30 \mathrm{~ns}$ and a peak voltage (PV) of 7-20 kV.

\section{Plasma-assisted synthesis of $\mathrm{Cu}$-based nanostructures}

In our experimental setup (Figure 1b), the CAP jet was used as cathode while a copper foil ( $2 \mathrm{~cm} \times 2$ $\mathrm{cm}$ ) was used as anode. The peak voltage and pulse repetition frequency of the generator driving the source were fixed at $7 \mathrm{kV}$ and $320 \mathrm{~Hz}$, respectively; 3 standard litres per minute (slpm) of Ar were used to sustain the plasma, which propagated in air across the gap $(1 \mathrm{~mm})$ between the nozzle of the CAP jet and the liquid solution. The distance between the plasma source and the copper foil was set at $3 \mathrm{~cm}$; the plasma treatment of the liquid solution lasted $30 \mathrm{~min}$.

In order to carefully investigate the chemistry induced by the plasma in the liquid environment, additional experiments were performed using an inert carbon rod as anode as a substitute for the copper foil.

Four distinct $6 \mathrm{~mL}$ aqueous electrolyte solutions (chemicals purchased from Sigma Aldrich) were employed for the process; Table 1 summarizes the respective composition and conductivity, where the latter was measured by means of a Eutech Cond $6+$ conductivity meter.

Table 1. Electrolyte solutions: chemical composition, conductivity and $\mathrm{pH}$ values

\begin{tabular}{lcccc}
\hline & $\begin{array}{c}\text { NaCl } \\
{[\mathrm{g} / \mathrm{mL}]}\end{array}$ & $\begin{array}{c}\mathbf{N a O H} \\
{[\mathrm{g} / \mathrm{mL}]}\end{array}$ & $\begin{array}{c}\text { Conductivity } \\
{[\mathrm{mS} / \mathrm{cm}]}\end{array}$ & $\mathbf{p H}$ \\
\hline SOL1 & 0.075 & 0.005 & $112.35 \pm 0.76$ & $12.81 \pm 0.03$ \\
SOL2 & 0.150 & - & $181.93 \pm 5.78$ & $5.91 \pm 0.25$
\end{tabular}


All the electrolyte solutions were produced starting from distilled water and $\mathrm{NaCl}+\mathrm{NaOH}$ (alkaline solution) or $\mathrm{NaCl}$ (acid solution) were used to vary the $\mathrm{pH}$. SOL3 contained only $\mathrm{NaOH}$ with the same concentration of SOL1 to understand the role of the base in the plasma-liquid processes occurring in SOL1. Finally, SOL4 contained only $\mathrm{NaOH}$ with a concentration sufficient to obtain the same conductivity of SOL1 so to discriminate the relevance of the chemical composition of the liquid environment with respect to its conductivity.

\section{Colloids characterization}

The $\mathrm{pH}$ of the solutions before and after $30 \mathrm{~min}$ of plasma exposure was measured by means of a $\mathrm{pH}$ meter (InLab Micro Pro). Analytic Quantofix test strips (Sigma Aldrich) were used to perform a semiquantitative analysis of $\mathrm{Cu}$ ions $\left(\mathrm{Cu}^{+/ 2+}\right)$, hydrogen peroxides, nitrates and nitrites concentrations (detection limits $5 \mathrm{mg} / \mathrm{L}, 0.5 \mathrm{mg} / \mathrm{L}, 5 \mathrm{mg} / \mathrm{L}, 0.5 \mathrm{mg} / \mathrm{L}$, respectively) in untreated solutions and colloids, as reported in [32].

\section{Protocol for samples characterization after nanostructures synthesis}

Colloids were washed by centrifuging ( $3000 \mathrm{rpm}$ for 1 hour) in water for 4 times and in ethanol for 4 times. After that, colloidal samples were transferred in glass vials, dried and further annealed at $300{ }^{\circ} \mathrm{C}$ for $3 \mathrm{~h}$. The samples were then re-dispersed in ethanol and ultra-sonicated for $10 \mathrm{~min}$ before drop-casting.

\section{Morphological and chemical characterizations of the nanostructures}

The morphology and chemical properties of the samples were analyzed by TEM and SAED (JEOL JEM-2100F), XRD (XRD, Bruker D8 Discover) and XPS (Kratos Anlytical, Japan). Samples were drop-cast on carbon coated Au grids and allowed to dry overnight before being used for TEM and SAED measurements. For XRD measurements, powder samples were directly drop-cast onto an XRD sample holder and scanned. For XPS measurements, samples were drop-cast on silicon substrates and dried.

\section{Results and Discussion}

\section{Characterization of the colloids}

The colour change in the solution after plasma treatment is often a qualitative indication of the nanostructures being formed $[4,16]$. In our experiments we observed a colour change after 10 minutes of plasma treatment only for SOL1 (brownish colour, Figure 2b) and SOL2 (greenish colour, Figure 
2d). Conversely, nanostructures were not synthesized in SOL3 and SOL4 and accordingly no colour change was observed.

$\mathrm{Cu}$ ions were detected in both the colloids produced by plasma treating SOL1 (SOL1 colloid) and SOL2 (SOL2 colloid); more specifically, a concentration in the range of $10-30 \mathrm{mg} / \mathrm{L}$ was detected in the SOL1 colloid and a concentration in the range of 100-300 mg/L was measured in the SOL2 colloid. SOL1 was initially extremely basic $(\mathrm{pH} 12.81 \pm 0.03)$ due to the presence of $\mathrm{NaOH}$ and no significant variations in $\mathrm{pH}$ were registered after the plasma treatment. However, the plasma process induced a dramatic alkalinisation of SOL2, with the $\mathrm{pH}$ increased from 5.91 \pm 0.25 to $10.35 \pm 0.22$. In both colloids, $\mathrm{NO}_{2}^{-}$(concentration in the range of 10-20 mg/L) and $\mathrm{NO}_{3}{ }^{-}$(concentration in the range 100-250 mg/L) anions were detected; these ions can originate from oxygen and nitrogen species formed by the interaction of the plasma plume with the surrounding environment air, which then dissolve into the liquid phase [8]. Finally, the concentration of $\mathrm{H}_{2} \mathrm{O}_{2}$ was below the detection limit for all the plasma treated solutions. Production of $\mathrm{Cu}^{+/ 2+}$ was not observed in SOL3 and SOL4 after plasma treatment, possibly due to the role of $\mathrm{NaCl}$ in promoting the anodic dissolution of the $\mathrm{Cu}$ foil, as observed in electrochemical cells [33-35]. These results are further summarized in Table 2.

Table 2. Concentrations of $\mathrm{Cu}^{+/ 2+}, \mathrm{NO}_{2}^{-}, \mathrm{NO}_{3}^{-}, \mathrm{H}_{2} \mathrm{O}_{2}$ and values of $\mathrm{pH}$ measured in SOL1, SOL2, SOL

\begin{tabular}{|c|c|c|c|c|c|c|c|c|}
\hline & SOL1 & $\begin{array}{l}\text { SOL1 } \\
\text { colloid }\end{array}$ & SOL2 & $\begin{array}{c}\text { SOL2 } \\
\text { colloid }\end{array}$ & SOL3 & $\begin{array}{c}\text { Treated } \\
\text { SOL3 }\end{array}$ & SOL4 & $\begin{array}{c}\text { Treated } \\
\text { SOL4 }\end{array}$ \\
\hline $\begin{array}{c}{\left[\mathrm{Cu}^{+/ 2+}\right]} \\
{[\mathrm{mg} / \mathrm{L}]}\end{array}$ & undetected & $10-30$ & undetected & $100-300$ & undetected & undetected & undetected & undetected \\
\hline $\begin{array}{l}{\left[\mathbf{N O}_{2}{ }^{-}\right]} \\
{[\mathrm{mg} / \mathrm{L}]}\end{array}$ & undetected & $10-20$ & undetected & $10-20$ & undetected & $10-20$ & undetected & $1-5$ \\
\hline $\begin{array}{l}{\left[\mathrm{NO}_{3}{ }^{-}\right]} \\
{[\mathrm{mg} / \mathrm{L}]}\end{array}$ & undetected & $100-250$ & undetected & $100-250$ & undetected & $10-20$ & undetected & $25-50$ \\
\hline $\begin{array}{l}{\left[\mathbf{H}_{2} \mathbf{O}_{2}\right]} \\
{[\mathrm{mg} / \mathrm{L}]}\end{array}$ & undetected & Undetected & undetected & undetected & undetected & undetected & undetected & undetected \\
\hline pH & $12.81 \pm 0.03$ & $12.73 \pm 0.15$ & $5.91 \pm 0.25$ & $10.35 \pm 0.22$ & $12.8 \pm 0.1$ & $12.7 \pm 0.1$ & $13.1 \pm 0.1$ & $13.2 \pm 0.1$ \\
\hline
\end{tabular}




\section{Morphology of the synthesized nanostructures}

Figure 3 reports the TEM images of the nanostructures obtained from SOL1 and SOL2. The plasma treatment of both solutions induced the production of nanorods and nanoparticles. However, the chemical composition of the electrolyte solutions did affect the produced nanostructures; while nanorods from both solutions were highly aggregated (Figure 3a and 3e), nanorods from SOL1 appeared to be longer (200-500 $\mathrm{nm}$ long) than those from SOL2 (<200 nm long). Also, nanorods in SOL2 presented a single crystal phase (Figure 3f) while a clear polycrystalline nature could be observed for nanorods from SOL1 (Figure 3b). In both cases the $\mathrm{CuO}$ phase could be confirmed by fast Fourier transform (FFT) analysis, as shown in the corresponding insets where planes separated by $0.24 \mathrm{~nm}$ have been observed as expected for $\mathrm{CuO}$. Crystalline nanoparticles with diameters below 10 $\mathrm{nm}$ could also be observed in both colloids (Figure 3c, 3d and 3h). Finally, some non-crystalline structures were observed in SOL2 (Figure 3g). SAED analysis (Figure 4) confirmed the presence of the $\mathrm{CuO}$ phase in both cases with also other crystalline structures among SOL2 products (Figure 4b); their chemical composition was identified by means of different characterization techniques as reported in the following section.

\section{Chemical composition and crystal structure of the synthesized nanostructures}

The chemical composition and crystal structure of the nanomaterials was further assessed by XRD and XPS analysis. Samples were obtained by drop-casting the colloids onto silicon substrates and dried, according to the procedure reported in Methods.

Figure 5 reports the XRD spectra collected for samples produced by plasma treating SOL1 and SOL2. XRD patterns clearly highlight that the peaks can be attributed to $\mathrm{CuO}$, presenting a monoclinic pure phase (Pattern: 01-089-5895)[36, 37]. However, samples produced from SOL2 also present two minor $\mathrm{NaCl}$ peaks. No characteristic peaks of any other copper containing compound could be detected from this analysis.

Figure 6 shows the XPS spectra collected for samples obtained from SOL1 and SOL2. The Cu $2 p$ core level binding energies just below $935 \mathrm{eV}$ and $955 \mathrm{eV}$ are attributed to the $\mathrm{Cu} 2 p_{3 / 2}$ and $\mathrm{Cu} 2 p_{1 / 2}$, respectively [36, 38]. The presence of the satellite peaks (from 940-946 eV and 960-965 eV) on the higher binding energy side of the $\mathrm{Cu} 2 p$ main peaks confirmed the formation of $\mathrm{CuO}$ phase rather than cuprous oxide $\left(\mathrm{Cu}_{2} \mathrm{O}\right)[38,39]$. Deconvolution of the two main $\mathrm{Cu} 2 p_{3 / 2}$ and $\mathrm{Cu} 2 p_{1 / 2}$ peaks was carried out on the basis of the following components: metallic copper (I), $\mathrm{CuO}$ phase (II) and a third peak to be ascribed to either the binding energy within $\mathrm{CuCl}_{2}$ or $\mathrm{Cu}(\mathrm{OH})_{2}$ (III).

Focusing on the nanostructures produced from SOL1 (Figure $6 \mathrm{a}$ and $6 \mathrm{~b}$ ), the wide scan spectrum (Figure 6a) underlines the presence of $\mathrm{Cu}$ and $\mathrm{O}$. The trace amount of silicon ( $\mathrm{Si}$ ), carbon (C) and sodium (Na) are due to the substrate, organic impurities and to the composition of the electrolyte solution, respectively. Selected areas of the wide scan were also recorded for $\mathrm{Cu} 2 p$ (Figure 6b). The de-convoluted $\mathrm{Cu} 2 p_{3 / 2}$ envelope exhibits a peak placed at $934.2 \mathrm{eV}$ (II) corresponding to $\mathrm{CuO}$ phase and a much less intense peak at $932.2 \mathrm{eV}$ (I) attributed to the presence of the $\mathrm{Cu}$ phase [40, 41]. The 
XPS wide scan does not indicate the presence of $\mathrm{Cl}$ and therefore the third low-intensity peak (III) has to be ascribed to $\mathrm{Cu}(\mathrm{OH})_{2}$. Finally, the $\mathrm{Cu} 2 p_{1 / 2}$ peak can be de-convoluted in the lower contribution of the metallic phase (I) and the stronger one of the oxidized phase (II).

Wide scan XPS spectra of nanostructures synthesized from SOL2 (Figure 6c) showed the presence of $\mathrm{Cu}, \mathrm{O}$ and traces of $\mathrm{Si}, \mathrm{C}$ and $\mathrm{Na}$, as already observed for nanostructures from SOL1. Additionally, the presence of $\mathrm{Cl}$ peaks at $268.6 \mathrm{eV}$ and $198.6 \mathrm{eV}$ can be attributed to the $\mathrm{CuCl}_{2}$ phase, as reported in a previous work [40]. This is confirmed from the analysis of the $\mathrm{Cu} 2 p$ peaks (Figure $6 \mathrm{~d}$ ), since the $\mathrm{Cu}$ $2 p_{3 / 2}$ and $\mathrm{Cu} 2 p_{1 / 2}$ are placed at slightly higher binding energy (934.8 eV and $954.7 \mathrm{eV}$, respectively) than the SOL1 case, in agreement with the contextual presence of $\mathrm{CuO}$ and $\mathrm{CuCl}_{2}$ phases [40]. The deconvolution is consistent with this analysis as the typical binding energies for $\mathrm{CuO}$ (II) and $\mathrm{CuCl}_{2}$ (III) can be fitted (Figure 6d) along with a negligible peak attributed to copper metal phase (I). However we cannot exclude the possibility that peak (III) originates from the $\mathrm{Cu}(\mathrm{OH})_{2}$ phase.

\section{Formation of nanostructures and reactions induced by plasma in liquid phase}

Based on the material characterization, both dispersed and aggregated nanoparticles and nanorods were produced in SOL1 and SOL2 colloids. SOL1 mainly yields $\mathrm{CuO}$ crystalline structures with limited impurities or unreacted products (e.g. Na as detected by XPS). A very limited amount of metallic $\mathrm{Cu}$ and $\mathrm{Cu}(\mathrm{OH})_{2}$ nanostructures are also revealed by XPS analysis (undetected by XRD). SOL2 also produces $\mathrm{CuO}$ crystalline structures together with by-products and unreacted compounds as observed by XPS (i.e. $\mathrm{CuCl}_{2}$ ) and XRD $(\mathrm{NaCl})$, respectively. Two coexisting reaction pathways leading to the synthesis of these $\mathrm{Cu}$-based nanostructures are here proposed.

\section{Pathway A:}

$\mathrm{Cu}+\mathrm{nCl}^{-}-\mathrm{e}^{-} \rightarrow \mathrm{CuCl}_{\mathrm{n}}{ }^{1-\mathrm{n}}$

$\mathrm{Cl}^{-}$, due to the dissociation of $\mathrm{NaCl}$ in water, reacts with metal $\mathrm{Cu}$ at the interface between the copper foil anode and the solution, producing $\mathrm{CuCl}_{n}{ }^{1-\mathrm{n}}[5] . \mathrm{CuCl}_{\mathrm{n}}{ }^{1-\mathrm{n}}$ ions move into the electrolyte solution which contains $\mathrm{Cl}^{-}$and $\mathrm{OH}^{-}$ions due to the natural dissociation of water and $\mathrm{NaOH}$ (if present) and to the dissociation of $\mathrm{H}_{2} \mathrm{O}$ molecules induced by plasma at the cathode of the electrochemical cell $[5,7$, 8]. $\mathrm{CuCl}_{\mathrm{n}}{ }^{1-\mathrm{n}}$ reacts with the electrolyte leading to the formation of copper oxychloride compounds, i.e. botallackite [42] or clinoatacamite [43], containing both $\mathrm{CuCl}_{2}$ and $\mathrm{Cu}(\mathrm{OH})_{2}$ phases. After the formation of these phases, the pathway proceeds according to the following reactions, depending on the $\mathrm{pH}$ of the solution:

$\mathrm{CuCl}_{2}+2 \mathrm{OH}^{-} \rightarrow \mathrm{Cu}(\mathrm{OH})_{2}+2 \mathrm{Cl}^{-}$

$\mathrm{Cu}(\mathrm{OH})_{2}+2 \mathrm{OH}^{-} \rightarrow \mathrm{CuO}+2 \mathrm{OH}^{-}+\mathrm{H}_{2} \mathrm{O}$

In an acidic solution, the equilibrium is shifted towards $\mathrm{CuCl}_{2}$, so the formation of $\mathrm{Cu}(\mathrm{OH})_{2}$ in (2) is limited [43]. Conversely, in an alkaline solution at room temperature, $\mathrm{CuCl}_{2}$ can react with $\mathrm{OH}^{-}$ leading to the formation of $\mathrm{Cu}(\mathrm{OH})_{2}$ in (2) [44]. before being converted to $\mathrm{CuO}$ according to (3) [45].

\section{Pathway B:}


$\mathrm{Cu} \rightarrow \mathrm{Cu}^{2+}{ }_{\text {aq }}+2 \mathrm{e}^{-}{ }_{\text {qq }}$

$\mathrm{Cu}^{2+}{ }_{\mathrm{aq}}+2 \mathrm{e}_{\mathrm{aq}}^{-} \rightarrow \mathrm{Cu}$

$\mathrm{Cu}+\mathrm{H}_{2} \mathrm{O}_{2} \rightarrow \mathrm{CuO}+\mathrm{H}_{2} \mathrm{O}$

In this second pathway (B), the first reaction (4) represents the metal dissolution occurring at the anode of the electrochemical cell [3]; the released $\mathrm{Cu}^{2+}$ ions then react with hydrated electrons in the bulk of the liquid, forming $\mathrm{Cu}$ according reaction (5) [3, 46]. Finally, in the bulk of the liquid, metal $\mathrm{Cu}$ can react with $\mathrm{H}_{2} \mathrm{O}_{2}$ molecules leading to the formation of $\mathrm{CuO}$ [46].

In alkaline solutions (SOL1, SOL3 and SOL4), $\mathrm{H}_{2} \mathrm{O}_{2}$ was not observed after plasma treatment, due to the high $\mathrm{OH}^{-}$concentration which leads to the $\mathrm{H}_{2} \mathrm{O}_{2}$ decomposition [47] according to the reaction:

$\mathrm{H}_{2} \mathrm{O}_{2}+\mathrm{OH}^{-} \rightarrow \mathrm{H}_{2} \mathrm{O}+\mathrm{HO}_{2}^{-}$

With SOL2 $(\mathrm{pH}$ before the treatment $=5.91 \pm 0.25)$ no $\mathrm{H}_{2} \mathrm{O}_{2}$ was detected after plasma treatment. However when the copper foil was replaced by a carbon rod, thus eliminating the nanomaterial synthesis, around $3 \mathrm{mg} / \mathrm{L}$ of $\mathrm{H}_{2} \mathrm{O}_{2}$ were detected in plasma treated solutions.. This is strong evidence that, with copper foil as electrode, the absence of $\mathrm{H}_{2} \mathrm{O}_{2}$ in SOL2 colloid is as a result of its complete consumption through the reaction with copper in (6).

Focusing on SOL1 (alkaline), at the anode of the electrochemical cell, $\mathrm{Cl}^{-}$ions can interact with metal $\mathrm{Cu}$ and form $\mathrm{CuCl}_{\mathrm{n}}{ }^{1-\mathrm{n}}$, which, in the highly alkaline solution $(\mathrm{pH}>12)$, is completely converted in $\mathrm{Cu}(\mathrm{OH})_{2}$. The $\mathrm{OH}^{-}$in the bulk of the liquid can then transform $\mathrm{Cu}(\mathrm{OH})_{2}$ into $\mathrm{CuO}$, according to reaction 3.The metal $\mathrm{Cu}$ dissolution enables the release of $\mathrm{Cu}^{2+}$ ions, which, reacting with hydrated electrons produced by plasma, can be reduced forming metal $\mathrm{Cu}$. The proposed mechanism is supported by the results of the characterization of the nanostructures, which revealed:

i. the presence of $\mathrm{CuO}$;

ii. the absence of $\mathrm{CuCl}_{2}$;

iii. the presence of $\mathrm{Cu}(\mathrm{OH})_{2}$. This can be ascribed to the incomplete conversion of $\mathrm{Cu}(\mathrm{OH})_{2}$ into $\mathrm{CuO}$, probably due to the rather low temperature $\left(20^{\circ} \mathrm{C}\right)$ of the liquid environment during the process. Indeed, previous studies demonstrated that temperatures around $50{ }^{\circ} \mathrm{C}$ are generally required for the complete conversion of $\mathrm{Cu}(\mathrm{OH})_{2}$ in $\mathrm{CuO}$ in an alkaline solution [48];

iv. the presence of $\mathrm{Cu}$. Due to the high alkalinity of the solution, $\mathrm{H}_{2} \mathrm{O}_{2}$ was completely consumed by the reaction with $\mathrm{OH}^{-}$and was not available for reacting with $\mathrm{Cu}$ to produce $\mathrm{CuO}$ according to reaction 6 .

In contrast, SOL2 is initially acid and its $\mathrm{pH}$ increases only gradually during the process ( $\mathrm{pH} 10.35$ at the end of the treatment) due to the plasma induced electrolytic reactions leading to the reduction of hydrogen ions to hydrogen gas $[8,46]$. This limits the efficiency of reaction 2 and makes reaction 6 possible, as $\mathrm{H}_{2} \mathrm{O}_{2}$ becomes available for reacting with $\mathrm{Cu}$, with the following effects: 
i. $\mathrm{CuCl}_{2}$ is not totally converted to $\mathrm{Cu}(\mathrm{OH})_{2}$, remaining as by-product at the end of the process, as revealed by XPS analysis;

ii. $\mathrm{CuO}$ is produced by the conversion of $\mathrm{Cu}(\mathrm{OH})_{2}$ by $\mathrm{OH}^{-}$, according to reaction 3 . Due to the initial acid $\mathrm{pH}$ of SOL2, the conversion is not complete and traces of $\mathrm{Cu}(\mathrm{OH})_{2}$ phase could be found at the end of the process;

iii. $\mathrm{CuO}$ is also produced, according to reaction 6 , between metal $\mathrm{Cu}$ and plasma produced $\mathrm{H}_{2} \mathrm{O}_{2}$. Due to the acid $\mathrm{pH}$ of the solution at the beginning of the process, $\mathrm{H}_{2} \mathrm{O}_{2}$ is not consumed by the $\mathrm{OH}^{-}$ions and the reaction between $\mathrm{H}_{2} \mathrm{O}_{2}$ and $\mathrm{Cu}$ can occur with the formation of $\mathrm{CuO}$. As a result, a lower amount of $\mathrm{Cu}$ is detected in SOL2 with respect to SOL1.

Finally, the presence of $\mathrm{NaCl}$ among the final products of SOL2, as detected by XRD, can be attributed to its initial concentration, which is higher in SOL2 than in SOL1; since $\mathrm{NaCl}$ has also been documented to promote the anodic dissolution of the $\mathrm{Cu}$ foil in an electrochemical cell [33-35], the higher $\mathrm{NaCl}$ concentration can be held responsible for the higher $\mathrm{Cu}$ ions concentration in SOL2 than in SOL1.

\section{Conclusions}

The results presented here highlight that the composition of the produced nanostructures as well as their crystalline properties depend on the chemical characteristics of the liquid environment used for the CAP assisted synthesis process.

The study has revealed: (i) the prevalent role of electrolyte chemical composition versus that of the conductivity; (ii) the fundamental role of $\mathrm{NaCl}$, which enables copper anodic dissolution; (iii) in an alkaline solution, the conversion of $\mathrm{CuCl}_{2}$ phase into the $\mathrm{CuO}$ phase; (iv) in an initially acidic solution, the formation of $\mathrm{CuO}$ as a result of the reaction between metallic $\mathrm{Cu}$ and plasma produced $\mathrm{H}_{2} \mathrm{O}_{2}$. Plasma-assisted electrochemistry is an innovative and complex field, in which many questions dealing with the role of process parameters on nanostructures' morphology and phases are still unanswered. In this context, the proposed study represents an attempt to identify the fundamental mechanisms driving the plasma-liquid interactions so that the characteristics of the liquid environment can be appropriately tuned to produce nanostructures with desired properties.

\section{References}

1. Graves DB (2012) The emerging role of reactive oxygen and nitrogen species in redox biology and some implications for plasma applications to medicine and biology. J Phys D Appl Phys 45:263001 . doi: 10.1088/0022-3727/45/26/263001 
2. Bruggeman P, Leys C (2009) Non-thermal plasmas in and in contact with liquids. J Phys D Appl Phys 42:053001 . doi: 10.1088/0022-3727/42/5/053001

3. Wei-Hung C, Carolyn R, Sankaran RM (2010) Continuous-flow, atmospheric-pressure microplasmas: a versatile source for metal nanoparticle synthesis in the gas or liquid phase. Plasma Sources Sci Technol 19:34011 . doi: 10.1088/0963-0252/19/3/034011

4. Patel J, Němcová L, Maguire P, et al (2013) Synthesis of surfactant-free electrostatically stabilized gold nanoparticles by plasma-induced liquid chemistry. Nanotechnology 24:245604 . doi: $10.1088 / 0957-4484 / 24 / 24 / 245604$

5. Du C, Xiao M (2014) Cu2O nanoparticles synthesis by microplasma. Sci Rep 4:7339 . doi: 10.1038/srep07339

6. Mariotti D, Patel J, Svrcek V, Maguire P (2012) Plasma-liquid interactions at atmospheric pressure for nanomaterials synthesis and surface engineering. Plasma Process Polym 9:10741085 . doi: 10.1002/ppap.201200007

7. Rumbach P, Bartels DM, Sankaran RM, Go DB (2015) The effect of air on solvated electron chemistry at a plasma/liquid interface. J Phys D Appl Phys 48:424001 . doi: 10.1088/0022$3727 / 48 / 42 / 424001$

8. Rumbach P, Witzke M, Sankaran RM, Go DB (2013) Decoupling interfacial reactions between plasmas and liquids: Charge transfer vs plasma neutral reactions. J Am Chem Soc 135:1626416267 . doi: $10.1021 / \mathrm{ja} 407149 \mathrm{y}$

9. Rumbach P, Griggs N, Sankaran RM, Go DB (2014) Visualization of electrolytic reactions at a plasma-liquid interface. IEEE Trans Plasma Sci 42:2610-2611 . doi: 10.1109/TPS.2014.2322976

10. Mariotti D, Sankaran RM (2010) Microplasmas for nanomaterials synthesis. J Phys D Appl Phys 43:323001 . doi: 10.1088/0022-3727/43/32/323001

11. Anžlovar A, Marinšek M, Orel ZC, Žigon M (2015) Basic zinc carbonate as a precursor in the solvothermal synthesis of nano-zinc oxide. Mater Des 86:347-353 . doi: 10.1016/j.matdes.2015.07.087

12. Yu-Ping Z, Lee S-H, Reddy KR, et al (2007) Synthesis and characterization of core $\square$ shell $\mathrm{SiO} 2$ nanoparticles/poly (3 $\square$ aminophenylboronic acid) composites. J Appl Polym Sci 104:2743-2750 . doi: 10.1002/app

13. Hassan M, Haque E, Reddy KR, et al (2014) Edge-enriched graphene quantum dots for enhanced photo-luminescence and supercapacitance. Nanoscale 6:11988-11994 . doi: 10.1039/C4NR02365J

14. Tan C, Zhang H (2015) Wet-chemical synthesis and applications of non-layer structured twodimensional nanomaterials. Nat Commun 6:7873 . doi: 10.1038/ncomms8873

15. Reetz MT, Helbig W (1994) Size-Selective Synthesis of Nanostructured Transition Metal Clusters. J Am Chem Soc 116:7401-7402 . doi: 10.1021/ja00095a051 
16. Richmonds C, Sankaran RM (2008) Plasma-liquid electrochemistry: Rapid synthesis of colloidal metal nanoparticles by microplasma reduction of aqueous cations. Appl Phys Lett 93:2013-2016 . doi: 10.1063/1.2988283

17. Furuya K, Hirowatari Y, Ishioka T, Harata A (2007) Protective Agent-free Preparation of Gold Nanoplates and Nanorods in Aqueous HAuCl4 Solutions Using Gas-Liquid Interface Discharge. Chem Lett 36:1088-1089 . doi: 10.1246/cl.2007.1088

18. Furusho H, Kitano K, Hamaguchi S, Nagasaki Y (2009) Preparation of Stable WaterDispersible PEGylated Gold Nanoparticles Assisted by Nonequilibrium Atmospheric-Pressure Plasma Jets. Chem Mater 21:3526-3535 . doi: 10.1021/cm803290b

19. Hieda J, Saito N, Takai O (2008) Exotic shapes of gold nanoparticles synthesized using plasma in aqueous solution. J Vac Sci Technol A Vacuum, Surfaces, Film 26:854 . doi:

$10.1116 / 1.2919139$

20. Jana N, Gearheart L, Murphy C (2001) Wet chemical synthesis of high aspect ratio cylindrical gold nanorods. J Phys ... 4065-4067

21. Rogach AL (2000) Nanocrystalline CdTe and CdTe(S) particles: Wet chemical preparation, size-dependent optical properties and perspectives of optoelectronic applications. Mater Sci Eng B Solid-State Mater Adv Technol 69:435-440 . doi: 10.1016/S0921-5107(99)00231-7

22. Dierstein A, Natter H, Meyer F, et al (2001) Electrochemical deposition under oxidizing conditions (EDOC): A new synthesis for nanocrystalline metal oxides. Scr Mater 44:22092212 . doi: 10.1016/S1359-6462(01)00906-X

23. Chang S-S and LC-L and WCRC (1997) Gold Nanorods: Electrochemical Synthesis and Optical Properties. J Phys Chem B 101:6661-6664 . doi: 10.1021/jp971656q

24. Wijesundera RP (2010) Fabrication of the $\mathrm{CuO} / \mathrm{Cu} 2 \mathrm{O}$ heterojunction using an electrodeposition technique for solar cell applications. Semicond Sci Technol 25:045015 . doi: $10.1088 / 0268-1242 / 25 / 4 / 045015$

25. Anandan S, Wen X, Yang S (2005) Room temperature growth of $\mathrm{CuO}$ nanorod arrays on copper and their application as a cathode in dye-sensitized solar cells. Mater Chem Phys 93:35-40 . doi: 10.1016/j.matchemphys.2005.02.002

26. Sun H, Harms K, Sundermeyer J, et al (2004) Aerobic Oxidation of 2,3,6-Trimethylphenol to Trimethyl-1,4-benzoquinone with Copper(II) Chloride as Catalyst in Ionic Liquid and Structure of the Active Species. J Am Chem Soc 126:9550-9551

27. Rubilar O, Rai M, Tortella G, et al (2013) Biogenic nanoparticles: Copper, copper oxides, copper sulphides, complex copper nanostructures and their applications. Biotechnol. Lett. 35:1365-1375

28. Boselli M, Colombo V, Ghedini E, et al (2014) Schlieren high-speed imaging of a nanosecond pulsed atmospheric pressure non-equilibrium plasma jet. Plasma Chem Plasma Process 34:853-869 . doi: 10.1007/s11090-014-9537-1 
29. Colombo V, Fabiani D, Focarete ML, et al (2014) Atmospheric Pressure Non-Equilibrium Plasma Treatment to Improve the Electrospinnability of Poly( L -Lactic Acid) Polymeric Solution. Plasma Process Polym 11:247-255 . doi: 10.1002/ppap.201300141

30. Liguori A, Pollicino A, Stancampiano A, et al (2016) Deposition of Plasma-Polymerized Polyacrylic Acid Coatings by a Non-Equilibrium Atmospheric Pressure Nanopulsed Plasma Jet. Plasma Process Polym 13:375-386 . doi: 10.1002/ppap.201500080

31. Liguori A, Traldi E, Toccaceli E, et al (2015) Co-Deposition of Plasma-Polymerized Polyacrylic Acid and Silver Nanoparticles for the Production of Nanocomposite Coatings Using a Non-Equilibrium Atmospheric Pressure Plasma Jet. Plasma Process Polym 1-10 . doi: 10.1002/ppap.201500143

32. Laurita R, Barbieri D, Gherardi M, et al (2015) Chemical analysis of reactive species and antimicrobial activity of water treated by nanosecond pulsed DBD air plasma. Clin Plasma Med 3:53-61 . doi: 10.1016/j.cpme.2015.10.001

33. Faita G, Fiori G, Salvadore D (1975) Copper behaviour in acid and alkaline brines-I kinetics of anodic dissolution in $0.5 \mathrm{M} \mathrm{NaCl}$ and free-corrosion rates in the presence of oxygen. Corros Sci 15:383-392

34. Yuan B, Wang C, Li L, Chen S (2009) Real time observation of the anodic dissolution of copper in $\mathrm{NaCl}$ solution with the digital holography. Electrochem commun 11:1373-1376

35. Kear G, Barker BD, Walsh FC (2004) Electrochemical corrosion of unalloyed copper in chloride media-a critical review. Corros Sci 46:109-135

36. Ethiraj AS, Kang DJ (2012) Synthesis and characterization of $\mathrm{CuO}$ nanowires by a simple wet chemical method. Nanoscale Res Lett 7:70 . doi: 10.1186/1556-276X-7-70

37. Balamurugan B, Mehta BR (2001) Optical and structural properties of nanocrystalline copper oxide thin films prepared by activated reactive evaporation. Thin Solid Films 396:90-96 . doi: 10.1016/S0040-6090(01)01216-0

38. Sun S, Zhang X, Sun Y, et al (2013) Facile water-assisted synthesis of cupric oxide nanourchins and their application as nonenzymatic glucose biosensor. ACS Appl Mater Interfaces 5:4429-4437 . doi: 10.1021/am400858j

39. Borgohain K, Singh J, Rama Rao M, et al (2000) Quantum size effects in CuO nanoparticles. Phys Rev B 61:11093-11096 . doi: 10.1103/PhysRevB.61.11093

40. Vasquez RP, Foote MC, Hunt BD (1989) Reaction of nonaqueous halogen solutions with YBa2Cu 3O7-x. J Appl Phys 66:4866-4877 . doi: 10.1063/1.343805

41. Krylova V, Andrulevicius M (2009) Optical, XPS and XRD studies of semiconducting copper sulfide layers on a polyamide film. Int J Photoenergy 2009: . doi: 10.1155/2009/304308

42. Drogowska M, Brossard L, Menard H (1987) Anodic copper dissolution in the presence of Clions at $\mathrm{pH}$ 12. Corrosion 43:549-552 . doi: 10.5006/1.3583899

43. Engelbrekt C, Malcho P, Andersen J, et al (2014) Selective synthesis of clinoatacamite 
$\mathrm{Cu} 2(\mathrm{OH}) 3 \mathrm{Cl}$ and tenorite $\mathrm{CuO}$ nanoparticles by $\mathrm{pH}$ control. J Nanoparticle Res 16: . doi:

$$
\text { 10.1007/s11051-014-2562-4 }
$$

44. Wang W, Liu Z, Liu Y, et al (2003) A simple wet-chemical synthesis and characterization of CuO nanorods. Appl Phys A Mater Sci Process 76:417-420 . doi: 10.1007/s00339-002-1514-5

45. Cudennec Y, Lecerf A (2003) The transformation of $\mathrm{Cu}(\mathrm{OH}) 2$ into $\mathrm{CuO}$, revisited. Solid State Sci 5:1471-1474 . doi: http://dx.doi.org/10.1016/j.solidstatesciences.2003.09.009

46. Velusamy T, Liguori A, Macias-Montero M, et al (2017) Ultra-small CuO nanoparticles with tailored energy-band diagram synthesized by a hybrid plasma-liquid process. Press Plasma Process Polym 1-39 . doi: 10.1002/ppap.201100001

47. Guo TX, Zhao Y, Ma SC, Liu ST (2012) Decomposition Characteristics of Hydrogen Peroxide in Sodium Hydroxide Solution. Adv Mater Res 610:359-362 . doi:

10.4028/www.scientific.net/AMR.610-613.359

48. Richardson HW (1997) Handbook of Copper Compounds and Applications

49. Witzke M, Rumbach P, Go DB, Sankaran RM (2012) Evidence for the electrolysis of water by atmospheric-pressure plasmas formed at the surface of aqueous solutions. J Phys D Appl Phys 45:442001 . doi: 10.1088/0022-3727/45/44/442001

\section{Figure legends}

Figure 1. Plasma source and process schematic. (a) Non-equilibrium atmospheric pressure plasma jet: plasma jet impinging onto a liquid surface; (b) experimental setup employed for the nanostructures synthesis in liquid environment

Figure 2. Solutions and colloids. (a) SOL1, (b) SOL 1 colloid, (c) SOL2, (d) SOL2 colloid. Brown and green colloids were produced by subjecting SOL1 and SOL2 to $30 \mathrm{~min}$ of plasma exposure, respectively

Figure 3. TEM images of nanostructures obtained from the plasma treatment of SOL1 (a-d) and SOL2 (e-g). Insets in (b) and (f) report the corresponding FFT.

Figure 4. Selective area diffraction pattern of the samples produced from SOL1 (a) and SOL2 (b). Red traces indicate $\mathrm{CuO}$ phase.

Figure 5. X-ray diffraction spectra of nanostructures obtained from SOL1 and SOL2. The spectrum of nanostructures obtained from SOL1 highlights the presence of $\mathrm{CuO}$ peaks; the spectrum of nanostructures produced from SOL2 reports the presence of $\mathrm{CuO}$ and $\mathrm{NaCl}$ peaks.

Figure 6. XPS spectra of nanostructures obtained from SOL1 (a, b) and SOL2 (c, d): wide scan spectra (a, c), $\mathrm{Cu} 2 p$ peaks and their deconvolution $(\mathbf{b}, \mathbf{d})$. The spectra collected from the analysis of nanostructures produced from SOL1 (a, b) showed the presence of $\mathrm{CuO}$ (peak II), $\mathrm{Cu}(\mathrm{OH})_{2}$ (peak III) and $\mathrm{Cu}$ (peak I) phases, while the spectra collected from SOL2 reported the presence of $\mathrm{CuCl}_{2}$ (peak III), $\mathrm{CuO}$ (peak II) and $\mathrm{Cu}$ (peak I) phases.

\section{Competing financial interests}

The authors declare no competing financial interests. 